\title{
A MEDIAÇÃO DA DANÇA DO VENTRE NA CONSTITUIÇÃO DO SUJEITO
}

\author{
The mediation of the dance in the constitution of subjectivity
}

\author{
Alice Casanova dos Reis ${ }^{a}$, Andréa Vieira Zanella ${ }^{\mathrm{b}}$ \\ ${ }^{a}$ Doutoranda em Psicologia Social na Universidade de São Paulo, São Paulo, SP - Brasil, e-mail: alicecasanova@yahoo.com.br \\ b Prof. a do Departamento de Psicologia e do Programa de Pós-Graduação em Psicologia da Universidade Federal de Santa Catarina, \\ Bolsista em produtividade do CNPq, Santa Catarina, SC - Brasil, e-mail: azanella@cfh.ufsc.br
}

\begin{abstract}
Resumo
Este texto relata uma pesquisa em que o dançar se constituiu como objeto de reflexão e prática para compreender o processo de constituição do sujeito. Investigaram-se os sentidos de si e de outros (re)produzidos por aprendizes de dança do ventre a partir do seu dançar, destacando-se o contexto relacional nesse processo. Foram sujeitos da pesquisa 14 meninas, entre 7 e 12 anos, alunas de dança do ventre, ministrada pela autora principal, em uma instituição formal de ensino. A coleta de dados procedeuse por meio de questionário, respondido pelos sujeitos, portfólio, produzido por cada aluna após uma apresentação pública do grupo e depoimento filmado. Analisou-se a interdiscursividade (Bakhtin, 2003) entre os enunciados dos sujeitos, das pesquisadoras e de teóricos da Psicologia Histórico-Cultural e da Dança. Como resultados, constatou-se que o ensino da dança oriental nos espaços escolares pode se constituir como educação ético-estética comprometida com a potencialização do sujeito e seu reconhecimento como devir polissêmico.
\end{abstract}

Palavras-chave: Constituição do sujeito; Dança do ventre; Relações estéticas. 


\begin{abstract}
The thematic subjectivity was focus of this research, that had for objective to investigate the directions of itself and others produced by learned of Bellydance pupils. The importance of the relationship context in this process was distinguished it. 14 girls had been citizens of the research, between 7 and 12 years, pupils of Bellydance given for the main author in a regular school. The data had been collected through a questionnaire, answered for the pupils and an album, produced for each pupil after a public presentation of the group. It was analyzed interdiscursivity (Bakhtin, 2003) enters the statements of the citizens, the researchers and theoreticians of Historical-Cultural Psychology and Dance. As result, one evidenced that the education of Eastern Dance in schools can consist as engaged ethical-aesthetic education with the effort of the life and its recognition in the multiple possibilities.
\end{abstract}

Keywords: Subjectivity; Bellydance; Aesthetic relations.

\section{INTRODUÇÃO}

O presente trabalho relata uma pesquisa que teve por objetivo investigar os sentidos de si e de outros (re)produzidos por aprendizes de dança do ventre a partir do seu dançar, refletindo sobre a mediação dessa atividade na constituição dos sujeitos. A pesquisa desenvolveu-se junto a uma escola de uma cidade de médio porte do Sul do Brasil, durante o ano letivo de 2005, com um grupo de alunas participantes da atividade extracurricular de dança do ventre, ministrada pela autora principal. O grupo era formado por 14 meninas, alunas regulares do ensino fundamental naquela escola.

Procurou-se, por meio das atividades desenvolvidas nas aulas de dança, desenvolver a expressividade artística e a criatividade das alunas, proporcionando-lhes espaços em que puderam experimentar novas possibilidades de objetivação e subjetivação na relação consigo mesmas e com os outros que lhes eram significativos.

Buscamos destacar o papel fundamental do contexto relacional em que o dançar se desenvolveu, tendo como aporte teóricoepistemológico o materialismo histórico e dialético. A partir dessa perspectiva, o ser humano é um sujeito histórico e social, que se constitui enquanto tal a partir de sua relação com os outros, sendo essa relação semioticamente media- da (Vygotsky, 2000). A qualidade dessas relações, por sua vez, é condição para se auferir as relações que o sujeito estabelece consigo mesmo, e a dança se apresenta nesse processo como mediação que possibilita o estabelecimento de "relações estéticas". Enfocaremos aqui os lugares ocupados pelas aprendizes nessas relações estéticas e as significações aí produzidas, por elas e pelos outros com os quais convivem.

As reflexões aqui apresentadas partiram das falas das aprendizes, buscando analisar os sentidos aí expressos, a partir dos aportes teóricos da Psicologia Histórico-Cultural (Vygotsky, 1990, 1999, 2000) e da dança (Dantas, 1999). Nessa perspectiva, o sujeito é um ser social, da e na história. A singularidade humana resulta da apropriação pelo sujeito dos sentidos que mediam as relações sociais das quais ativamente participa. Como nos aponta Molon (1999, p. 69):

Neste universo de discussão centralizado na concepção semiótica do sujeito, ele constituise pelo outro e pela linguagem por meio de processos de significação e dos processos dialógicos, rompendo com a dicotomia entre sujeito e social, entre eu e o outro.

A compreensão do papel fundamental da linguagem no processo de constituição do sujeito aponta para a necessidade de entendermos o sujeito

\footnotetext{
Por relações estéticas compreendemos as relações em que se destaca a mediação do sensível, da criatividade e a abertura de sentidos, constituindo-se o sujeito nessa situação como criador ou contemplador de um objeto reconhecido como estético (Vázquez, 1999).
} 
no seu contexto, este entendido enquanto texto com, ou seja, co-produção de sentidos por sujeitos em relação. Ao nos perguntarmos sobre os sentidos produzidos pelas aprendizes a partir do seu dançar, estaremos destacando essa dimensão constitutiva e relacional da linguagem. Nesse sentido, a fala do outro é constituinte do eu, pois, como sublinha Bakhtin (2003, p. 402): “...essas 'palavras-alheias' são reelaboradas dialogicamente em 'minhas-alheiaspalavras' [...] e em seguida [nas] minhas palavras." Contextos formais de ensinar e aprender, enquanto espaços privilegiados de educação em nossa sociedade, têm uma importância fundamental nesse processo. Primeiro porque neles a criança é colocada em contato com uma determinada cultura científica, social e historicamente produzida pela humanidade e reconhecida como seu legado às novas gerações. Segundo porque, no processo de apropriação dessa cultura, a criança participa ativamente na produção das significações que mediam as relações sociais aí travadas, sendo ao mesmo tempo produzida por elas: "Contextos de ensinar e aprender são, portanto, contextos de produção de significações em que os sujeitos em relação ativamente produzem aos outros como a si mesmos" (Zanella, Da Ros, Reis, França, 2004, p. 96).

As relações interpessoais em contextos de escolarização formal trazem, no modo como se configuram, a especificidade de seu objetivo principal e que diz respeito à função socialmente reconhecida da escola: o ensino e a aprendizagem de conhecimentos científicos. Em razão disso, a dimensão cognitiva ganha maior visibilidade e é mais valorizada, apesar de reconhecermos que a totalidade do sujeito está implicada no processo de ensinar e aprender. Isso significa reconhecer que, mais do que conhecimentos científicos, as salas de aula são espaços onde circulam e são (re)produzidos (in)tensamente vontades, desejos, emoções, costumes, valores, modos de ser, corpos, pessoas.

Essas pontuações se fazem necessárias para entendermos o lugar da atividade artística na escola, e a especificidade das relações por ela mediadas. Consideramos o fazer artístico como uma atividade onde os sentimentos se destacam, pois “... a arte é uma técnica social do sentimento, um instrumento da sociedade através do qual incorpora ao ciclo da vida social os aspectos mais íntimos e pessoais do nosso ser" (Vygotsky, 1999, p. 315).

Desse modo, a atividade artística possibilita a produção de sentidos mediada pela afetividade, abrindo espaço, na relação consigo mesmo e com o outro, para a expressão de sensibilidades, inaugurando relações estéticas². Essas relações caracterizam-se por uma percepção sensível em que o sujeito "põe em jogo tudo que é como ser que sente, pensa e padece" (Vázquez, 1999, p. 146).

Definimos essa percepção sensível que caracteriza a relação estética como "olhar estético" (Reis, Zanella, França, Da Ros, 2004, p. 51), um olhar que, para além do ato fisiológico da percepção, não apreende a realidade como dado, mas a reconhece como multifacetada e polissêmica, ampliando suas possibilidades significativas.

A partir daí, destaca-se a importância da inserção da atividade artística nos contextos escolares, pois por meio dela o sujeito pode vivenciar novas possibilidades de expressão e (re)significação de si, na dialética entre subjetivação e objetivação mediada pela criação artística (Zanella, Reús, Camargo, Maheirie, França \& DaRos 2005). No caso da dança, arte específica que nesta pesquisa enfocamos, essa expressão acontece por meio do corpo, pois é no corpo que a criação se objetiva e este é uma dimensão fundamental através do qual o sujeito se constitui: “... o corpo é o homem que se exterioriza, é o que me liga aos outros e ao mundo, é aquilo por meio de que eu me expresso e tomo consciência de mim mesmo" (Garaudy, 1980, p. 181).

O corpo, portanto, enquanto realidade biopsicossocial, é fundamento e expressão de um sujeito que é corpo criado e constantemente recriado nas vivências cotidianas, nas práticas sociais das quais o sujeito ativamente participa, sejam estas deliberadas ou não, conscientes ou inconscientes, efêmeras ou duradouras. Nessas práticas, os sujeitos (re)inventam criativamente seus modos de ser, de viver e de estar com outros. Assim, partindo de uma concepção não inatista sobre a criatividade (Zanella, Da Ros, Reis, França, 2003, 2004), destaca-se a importância da

\footnotetext{
$\overline{2}$ Importante esclarecer que as relações estéticas não se estabelecem somente via arte, porém é a partir do recorte artístico que aqui as enfocamos. Sobre estética, vide Vázquez (1999).
} 
inserção nos espaços escolares de práticas psicossociais que possibilitam o desenvolvimento de atividades criadoras.

Segundo Vygostky (1990), a criatividade existe enquanto ação criadora que envolve a reelaboração de fragmentos da realidade, ou seja, a recombinação de aspectos variados através da imaginação, em um processo que envolve cognição, vontade e afetos, gerando um produto que, ao se objetivar, traz consigo algo novo, transformando a realidade da qual partiu e ao mesmo tempo o seu criador.

$\mathrm{Na}$ dança, a realidade da qual se parte é o corpo, na sua intersecção entre o biológico e o cultural, o qual ganha outras formas na medida em se trans-forma pelo movimento: "A dança possibilidade de arte inscrita no corpo - é metáfora do pensamento e realidade desse mesmo corpo. Realidade do corpo, pois é nele que a dança se estrutura. [...] A dança é o corpo transfigurandose em formas" (Dantas, 1999, p. 24-25).

$\mathrm{Na}$ dança, diferentemente das artes plásticas ou da literatura, a matéria a ser trabalhada, a ser transformada em obra, não é algo externo ao sujeito, mas é ele próprio, o seu corpo, que, todavia, não é um corpo simplesmente, mas um corpo que foi esculpido com os diversos sentidos que (con)formam o sujeito. O corpo é aqui compreendido a partir de Espinosa (1989), filósofo cujo monismo entre corpo e alma ressoa na obra vygotskyana ${ }^{3}$, ou seja, como organicidade simbólica, considerandose razão e emoção como indissociáveis.

É sobre este corpo, afetivo-simbólico, que a dança, enquanto técnica do movimento, insere suas marcas, reconfigurando-o, conforme explica Dantas (1999, p. 28): "quem dança transforma o seu próprio corpo, se molda e se remodela, se reconfigura". A dança, portanto, pode a partir dessa transformação do corpo engendrar mudanças na subjetividade daquele que dança.

\section{MÉTODO}

Para desenvolver esta pesquisa, baseamonos em uma perspectiva dialógica, que reconhece a necessidade de se estudar o sujeito a partir dos enunciados ${ }^{4}$ que produz no contexto a ser investigado, assim como a implicação do pesquisador na produção e interpretação desses enunciados (Bakhtin, 1999, 2003). Assim, procuramos neste estudo dar voz às alunas de dança do ventre, colhendo seus depoimentos sobre essa atividade através de três instrumentos: um questionário (aplicado após 6 meses do início das atividades), com perguntas que as alunas responderam por escrito; um porffólio, produzido por elas após a apresentação do grupo em um evento cultural do colégio, na semana do Dia das Crianças; e o depoimento das alunas no encerramento da atividade, registrado em fita VHS.

O questionário constituía-se de perguntas abertas, que foram respondidas individualmente, $\mathrm{e}$ sua aplicação ao grupo durou em média 30 minutos. As questões visavam a apreender os significados apropriados pelas alunas sobre a dança que estavam aprendendo e os sentidos que atribuíam a si mesmas como sujeitos dessa atividade.

O portfólio teve como objetivo o registro, em forma plástica e textual, da experiência vivida durante a apresentação da dança para o público. A sua confecção foi proposta na aula seguinte à apresentação e, para tanto, foram disponibilizados materiais variados, como papéis A4, lápis de cor e canetinhas. As alunas criaram um pequeno livreto, desenhando e colorindo na capa a sua representação como bailarina e redigindo em seu interior uma narrativa pessoal sobre o acontecimento. Elas puderam elaborar seus portfólios livremente, sendo que em média levaram uma hora para a realização do registro. $\mathrm{Na}$ aula seguinte, cada aluna apresentou seu livreto, mostrando o desenho e lendo a narrativa para o grupo. Procedeu-se, dessa forma, à reflexão coletiva sobre a apresentação de dança e as vivências de cada uma, em especial sobre como se sentiram ao dançar (muitas pela primeira vez) para o público.

Os depoimentos foram filmados em fita VHS durante a confraternização que marcou o encerramento anual das atividades, quando as alunas apresentaram duas coreografias para o público, formado em sua maioria pelos pais. Depois

\footnotetext{
3 Assim como em Espinosa (1989) encontramos uma ligação intrínseca entre idéias e afecções, em Vygotsky (2000) encontramos uma base afetivo-volitiva para o pensamento.

4 Bakhtin (1999) apresenta o conceito de enunciação para referir-se à vinculação da fala do sujeito com outras falas, pois considera que há sempre algum interlocutor, presente ou ausente, que é referência para a fala do sujeito e também sua audiência.
} 
de dançarem, conversarem, comerem, brincarem, a professora propôs uma roda de despedida em que cada uma falasse o que as aulas de dança do ventre tinham proporcionado a elas.

Dentre a totalidade do material coletado por meio dos procedimentos descritos, foram selecionados os enunciados mais significativos para os objetivos deste estudo. Essa seleção realizou-se a partir da leitura exaustiva das falas registradas, agrupando-se os enunciados, a partir do seu conteúdo, em eixos temáticos de significação, a partir dos quais a análise se desenvolveu. Esta procurou realizar-se por meio da interdiscursividade entre as falas dos sujeitos e das pesquisadoras, lembrando que "Toda interpretação é o correlacionamento de dado texto com outros" (Bakhtin, 2003, p. 400). Nessa via metodológica, o pesquisador se constitui como parte integrante do evento pesquisado, pois se entende que “... o interpretador é parte do enunciado a ser interpretado, do texto (ou melhor, dos enunciados, do diálogo entre estes), entra nele como um novo participante" (Bakhtin, 2003, p. 329).

\section{RESULTADOS}

Nas falas das pequenas bailarinas, encontramos múltiplos sentidos, sentidos produzidos por elas a partir da sua própria vivência da dança e sentidos por elas apropriados a partir da interação dialógica com os outros que as assistiram dançar. Nesta análise apresentamos três eixos temáticos em torno dos quais se desenvolveu essa produção de sentidos de si e dos outros, mediada pela dança.

\section{O sentido corporal de si}

Agrupamos neste eixo temático as falas em que a produção de sentidos pelas alunas remeteu a um referencial interno, da sua própria sensibilidade ao dançar. Assim, nestes enunciados, o dançar foi significado pelas alunas como uma atividade mobilizadora de diversas sensações corporais, constitutivas de sua subjetividade.

É a partir de um sentido cinestésico, referente às sensações corporais durante a execução dos movimentos, que uma das alunas falou de sua experiência com a dança do ventre:
"Para mim é uma dança que faz o nosso corpo se soltar" $\left(\mathrm{Maria}^{5}\right)$. Se a dança faz o corpo se soltar, então antes ele estaria preso? Mas a quê? No relato da apresentação, Maria afirma: "No começo eu estava dura, não conseguia dançar, mas depois eu me soltei". Podemos pensar que talvez a dança tenha possibilitado a Maria uma forma diferente de se relacionar com o próprio corpo no espaço escolar, mais livre em sua expressão. Isso porque a dança acontecia depois de encerrado o turno de aulas, de modo que o corpo, que havia permanecido horas sentado e relativamente silenciado, estava então liberado para "se soltar".

Também podemos pensar que a dança libera o corpo dos condicionamentos que balizam e ao mesmo tempo restringem os movimentos do sujeito no seu cotidiano, seja ele de trabalho ou estudo. Isso porque nela o foco de atenção está no próprio corpo, onde o movimento não é automático, dado ou imposto, mas é criado ativamente pelo sujeito como movimento expressivo em que reintegra harmoniosamente o fazer e o sentir. Essa reintegração é possível com o auxílio da propriocepção, a qual "é como revirar o corpo, é como vê-lo e ouvi-lo inteiramente. É como degustar o sabor do movimento" (Dantas, 1999, p. 111).

Para as participantes desta pesquisa, qual foi o sabor dos movimentos aprendidos e dançados? Para Cristina, foi o seguinte: "Eu me senti leve como uma pluma, fiquei à vontade". A leveza é uma das qualidades plástico-cinestésicas dos movimentos na dança do ventre, especialmente movimentos ondulatórios e giros, através dos quais a bailarina experimenta seu corpo numa nova relação com o tempo e o espaço, liberando-o dos vínculos usuais com a gravidade e a inércia muscular. Essa relação é regida, entre outros fatores, pelo ritmo, aspecto a partir do qual Patrícia significou a atividade investigada: "Para mim a dança do ventre é uma dança que tem que ter ritmo".

Segundo Dantas (1999, p. 19), “... o ritmo organiza o fluxo de energia do movimento através do tempo e do espaço". Contudo, na dança, a finalidade dessa organização está desvinculada da demanda cotidiana do trabalho e/ou estudo, no qual o corpo é solicitado à ação, tendo em vista um fim exterior a ela, ou seja, a ação é liberada de uma finalidade prático-utilitária e experimentada como um fim em si mesma.

\footnotetext{
5 Os nomes que aparecem neste trabalho são todos fictícios, para que a identidade das alunas seja preservada.
} 
Libertado da exigência de produção, o sujeito pode movimentar-se na dança pelo próprio prazer do movimento, estabelecendo com seu corpo uma relação estética, de fruição.

\section{O sentido emocional de si}

$\mathrm{Na}$ relação estética mediada pela dança, o corpo se constitui como centro irradiador e convergente de múltiplos sentidos. Esses sentidos enraizados no corpo ensejam diferentes estados emocionais, positivos ou negativos, que chegam à consciência dos sujeitos, sendo por eles apreendidos significativamente como sentimentos - de felicidade, orgulho, vergonha. Em suas narrativas, as alunas destacaram diferentes emoções e sentimentos:

A apresentação da dança do ventre foi muito emocionante, o resultado da dança foi positivo, mas no final eu errei, mas fingi que nem percebi. O grupo colaborou e a dança ficou ótima, no começo fiquei envergonhada, mas no meio fiquei ansiosa (Patrícia).

Eu senti muita alegria, pois com essa dançapodemos nos divertir (Maria).

Nós viemos ensaiando desde o início do ano para apresenta. O dia se aproxima, ele chega, antes da apresentação nos vestimos, maquiamos e vamos para a apresentação. Eu estava me sentindo feliz, na boa, mas um pouco 'aguniada'. Vamos para apresentar, tentei me concentrar, tentei achar minha mãe, não achei, me concentrei e não errei, acabou. Fui para a sala para me vestirnovamente, volteipara oginásio, achei minha mãe, fiquei o resto das apresentações lá [...] Minha mãe achou muito legal, a mais bonita de todas apresentações e eu mais ainda! (Lúcia).

Ao produzirem as narrativas acima transcritas, as alunas objetivaram os vários sentimentos que experimentaram ao dançar. Pode-se analisar que estes foram sentimentos que naquele momento vivido mediaram a constituição da sua subjetividade, contribuindo para que então se tornassem na referida ocasião: felizes, nervosas, ansiosas, envergonhadas, orgulhosas, alegres, angustiadas, concentradas, bonitas, admiradas pelo outro, reconhecidas.

Percebe-se que às vezes foram contraditórias as emoções experimentadas pelas pequenas bailarinas ao se apresentarem para o público (orgulho e vergonha em Patrícia, felicidade e angústia em Lúcia). Apesar disso, na fala de Cristina parece que os sentimentos de um modo geral puderam encontrar uma via de expressão na dança: " $A$ dança do ventre é o modo de uma bailarina se expressar através de seus movimentos" (Cristina).

Pode-se analisar que, encontrando na própria dança uma via para sua manifestação, talvez esses sentimentos, artisticamente objetivados, puderam desse modo ser transformados, produzindose como síntese a essa contradição um resultado positivo, como afirmou Patrícia. Esse seria o processo de catarse das emoções, proporcionado pela arte, no qual “.... as emoções angustiantes e desagradáveis são submetidas a certa descarga, à sua destruição e transformação em contrários..." (Vygotsky, 1999, p. 270). Nesse sentido, é singular a descrição por meio da qual Ariane registrou no portfólio sua primeira experiência de dançar para o público:

\begin{abstract}
Na sexta-feira a dança do ventre apresentou, no começo en estava muito agitada. Quando comecei a dançar eu estava me achando muito concentrada, no fim eu comecei a chorar pois en gostei muito e um menino estava me olhando e minha familia. A minha familia disse que a apresentação estava nota dez. e que esta apresentação foi melhor do que o ano passado.
\end{abstract}

As palavras de Ariane são representativas de uma (in)tensa vivência afetiva, em que o prazer de dançar e a alegria de mostrar o resultado produzido ao longo de muitos ensaios transbordaram em choro, ao constatar a presença e o reconhecimento de pessoas queridas por ela. Pode-se a partir daí cogitar que a dança abriu para as meninas investigadas um espaço de contato, legitimação e apropriação significativa das próprias emoções, respeitando-se como válidas a expressão das diferentes tonalidades emocionais que constituem a vida afetiva do sujeito na sua interação com os outros.

\section{Movimento dialógico dos sentidos de si e de outros}

Neste eixo temático reunimos os enunciados em que os sentidos expressos pelas alunas acerca da vivência da dança apareciam vinculados aos outros, ou seja, aos espectadores e ao modo como interagiram dialogicamente com elas nessa atividade. Isso apareceu em diversas falas, como nesta em que uma das alunas afirma: "Foi muito legal na hora da apresentação, tinha um monte de gente nos olhando..." (Viki). Qual o sentido 
desse olhar? Pode-se analisar que a qualidade do olhar do outro à pequena bailarina foi fundamental na significação de sua experiência de dançar.

Os sentidos produzidos pelos outros que assistiram à dança apresentada e percebidos pelas crianças através de seus olhares, de seus sorrisos, de seus gestos e palavras de aprovação ou, porventura, desaprovação, foram por elas apropriados, de modo que nesse movimento dialético o sentido de si se produziu também a partir do sentido do outro. Com isso, destacamos a participação da alteridade na constituição da subjetividade das alunas na dança.

$\mathrm{Na}$ relação de ensino-aprendizagem da dança investigada essa participação do outro na constituição do eu aparece na fala de uma aluna:

Na apresentação, me achei muito sorridente, neste ano foi o melhor de todos. O ano passado a prof. não era a mesma, a desse ano é muito mais exigente e também ensina muitos passos e nos faz repeti-los. Também ela faz brincadeiras e ensaia conosco algumas coreografias. Nossa apresentação em comparação com as outras foi um sucesso! (Maribel).

Pode-se analisar a mediação pedagógica na constituição da subjetividade das alunas a partir dos aspectos trazidos por Maribel em seu depoimento. Assim, destacamos primeiramente que, no ensino-aprendizagem da dança, “... a construção do corpo não pode ser vista apenas como corpo individual que eu construo, mas se trata de um corpo que eu construo sob o olhar do outro e para que ele possa ser olhado pelo outro" (Santin, 1995, p. 41). Na dança, o corpo é construído socialmente a partir da apropriação da sua técnica, um aprendizado que se faz sob o olhar de um outro (a professora) e cujo produto, a coreografia, é criado para ser olhado pelos muitos outros (o público).

Pode-se interpretar na fala de Maribel as diferentes ações da professora (ensinar os passos, fazer as alunas os repetirem, ser exigente, fazer brincadeiras e ensaiar coreografias) como algumas formas por meio das quais esse olhar do outro participou ativamente do processo em questão. O olhar atento da professora mediou um aprendizado corporal que, a partir da apresentação realizada, foi percebido como um sucesso por Maribel, resultado da disciplina dos exercícios, mas também do caráter lúdico que permeou as aulas de dança.

No movimento dialógico entre os sentidos de si e de outros produzidos na atividade da dança, além da relação com a professora, também se destacou nas falas das alunas a relação com os espectadores, a qual aparece, por exemplo, no seguinte relato:

\section{Quando acabei de apresentar todo mundo aplaudiu e quem veio assistir da minha familia disse que todas dançaram bem e uma das melhores danças que se apresentou foi a gente. Eu gostei muito de dançar e queria neste ano apresentar mais uma vez. Foi muito legal! (Lila)}

Pode-se analisar que os aplausos do público, ou seja, o reconhecimento de si pelo outro na dança, intensificaram em Lila um sentido positivo de si mesma naquela atividade, mobilizando-a a desejar apresentar-se novamente, ou seja, transformando a dança em um projeto de futuro a partir do qual sua subjetividade presente se constituiu.

Todas as alunas se remeteram na narrativa da apresentação aos familiares que as assistiam, indicado-nos a importância destas figuras de referência na constituição da subjetividade mediada pela dança no contexto investigado, como se vê no seguinte depoimento:

\section{A minha família adorou, minha vó, meu vô, minha mãe e meu pai e quem seja. Eu estava feliz, eu não olhei pro chão nem pro teto, eu acho que a nossa apresentação foi a mais bonita, a nossa roupa brilhou sabe, porque as luzes foram até nossa roupa e aí brilbou bastante (Márcia).}

O sentido do belo aparece na fala de Márcia como um dos aspectos presentes na sua experiência de dançar. Mas não apenas as luzes e o brilho das roupas contribuíram para que ela se sentisse feliz e significasse sua dança como a mais bonita, pois também o olhar dos outros, a admiração dos seus familiares, iluminaram a pequena dançarina. Segundo Bakhtin (2003, p.48), "só em relação ao outro eu vivencio imediatamente a beleza do corpo humano." Assim, podemos analisar que foi a partir da apreciação estética demonstrada pelos que a assistiam que Márcia reconheceu em si e nas colegas a beleza da dança que o grupo apresentou.

$\mathrm{Na}$ fala de outra aluna, o belo novamente aparece como central na significação da dança para os sujeitos:

Minha mãe disse bem assim: "Parabéns, filha, sua dança foi a melhor, a mais bonita!"'Fiquei contentepelo elogio. Todas ficaram bonitas e fizemos muito sucesso no 
colégio e todos assobiaram e bateram palmas, foi o melhor dia da minha vida, por isso adoro a dança do ventre (Patricia).

Neste enunciado, percebe-se claramente o movimento por meio do qual o sujeito fala de si, apropriando-se da fala do outro sobre si, pois Patrícia fala que todas ficaram bonitas, após citar o que lhe disse sua mãe, parabenizando-a por sua dança ter sido a melhor e mais bonita. Para Patrícia, no momento narrado por ela, os sentidos produzidos pelo outro e objetivados em suas palmas, assobios, olhares, palavras foram importantes na construção da imagem de si e no fortalecimento de sua autoestima, contribuindo para que ela concluísse: "foi o melhor dia da minha vida, por isso adoro a dança do ventre" (Patrícia). Nesse movimento dialógico, percebemos, portanto, que a participação do espectador foi fundamental na produção de sentidos mediada pela dança e na constituição da subjetividade dos sujeitos dessa atividade.

\section{CONSIDERAÇÕES FINAIS}

$\mathrm{Na}$ dança, o corpo se trans-forma, pois vivencia outras formas de se mover, ao mesmo tempo em que o sujeito nesse movimento experimenta outras formas de ser. Para os sujeitos investigados, meninas que em sua maioria estavam iniciando seu aprendizado da dança do ventre, foi importante nesse processo a relação que estabeleceram, por meio da dança, com outras pessoas.

A partir da análise realizada, compreendemos que no processo de constituição das alunas mediado pela dança do ventre, as falas, os gestos, os olhares da professora, das colegas, do público (em especial dos familiares) fizeram parte de uma interação dialógica, verbal e não-verbal, entre os sujeitos. Nessa interação, a constituição da singularidade de cada uma das jovens bailarinas foi construída não individualmente, mas na coletividade das relações interpessoais e estéticas, mediadas pela dança.

Nessas relações, conforme nos apontaram as falas dos sujeitos, os sentidos atribuídos pelas meninas a si mesmas enquanto bailarinas se fundaram e se complementaram na leitura que o outro produziu acerca da dança, leitura que, desse modo, ao ser apropriada por elas, reinventou as possibilidades de significação sobre o eu, pois "eu vivo em um mundo de palavras do outro" (Bakhtin, 2003, p. 379). A análise, portanto, leva à compreensão de que, no contexto investigado, a dança do ventre contribuiu para singelas transformações nos sujeitos dessa atividade, a partir do contexto dialógico em que tiveram lugar o aprendizado e a apresentação da dança. Nesse contexto, a produção de sentidos corporais, emocionais, de si e de outros - foi um movimento coletivamente criado.

Concluímos que a pesquisa realizada abre um caminho para futuras reflexões que abordem com maior profundidade a questão do ensino da dança nos espaços escolares. Com isso, poderá ser confirmada e melhor desenvolvida a possibilidade que se nos apresentou com o presente estudo: inserir a dança na escola como uma proposta concreta de educação estética. Educação que é também ética, pois comprometida com a potencialização do sujeito e seu reconhecimento como devir polissêmico. Educação (est)ética na qual o eu se (re)cria nas e pelas relações estéticas com os outros.

\section{REFERÊNCIAS}

Bakhtin, M. M. (1999). Marxismo e filosofia da linguagem: Problemas fundamentais do método sociológico na ciência da linguagem. (9a ed). São Paulo: Hucitec.

Bakhtin, M. M. (2003). Estética da criação verbal. (4a ed). São Paulo: Martins Fontes.

Dantas, M. (1999). Dança: o enigma do movimento. Porto Alegre: UFRGS.

Espinosa, B. de. (1989). Ética. (Os Pensadores, 4a ed). São Paulo: Nova Cultural.

Garaudy, R. (1980). Dançar a vida. Rio de Janeiro: Nova Fronteira.

Molon, S. I. (1999). Subjetividade e constituição do sujeito em Vygotsky. São Paulo: Educ.

Reis, A. C. dos, Zanella, A., França, K.B., \& Da Ros, S. (2004). Mediação pedagógica: reflexões sobre o olhar estético em contexto de escolarização formal. Psicologia: Reflexão e Crítica, 17(1), 51-60.

Santin, S. (1995). Educação física: Ética, estética, saúde. Porto Alegre: EST. 
Vázquez, A. S. (1999). Convite à estética. Rio de Janeiro: Civilização Brasileira.

Vygotsky, L. S. (1990). La imaginacion y el arte em la infância. Madri: Akal.

Vygotsky, L. S. (1999). Psicologia da arte. São Paulo: Martins Fontes.

Vygotsky, L. S. (2000). A construção do pensamento e da linguagem. São Paulo: Martins Fontes.

Zanella, A., Da Ros, S., Reis, A. C. dos, \& França, K. B. (2003). Concepções de Criatividade: movimentos em um contexto de escolarização formal. Psicologia em Estudo, Maringá, 8(1), 143-150.
Zanella, A., Da Ros, S., Reis, A. C. dos, \& França, K. B. (2004). Doce, Pirâmide ou Flor?: o processo de produção de sentidos em um contexto de ensinar e aprender. Interações, 9(17), 91-108.

Zanella, A., Reis, A. C. dos, Camargo, D., Maheirie, K., França, K., \& Da Ros, S. (2005). Movimento de Objetivação e Subjetivação, mediado pela criação artística. Psico-USF, 10(2), 191-199.

Recebido: 14/02/2008

Received: 02/14/2008

Aprovado: $03 / 03 / 2008$

Approved: 03/03/2008 